Article

\title{
Toward a Human-Centered Economy and Politics: The Theory of Justice as Fairness from Rawls to Sen
}

\author{
Alfonso D'Amodio \\ The International Research Area on Foundations of the Sciences (IRAFS), Pontifical Lateran University, \\ 00184 Rome, Italy; irafs@pul.it; Tel.: +39-329-439-7126
}

Received: 11 September 2020; Accepted: 2 December 2020; Published: 8 December 2020

\begin{abstract}
In this paper, I present the suggestion that a suitable theory of "justice as fairness" could offer a consistent path for solving many issues related to the actual crisis of the classical liberal model of economy and democracy, by substituting the abstract "equality" principle, with the concrete "equity" one in the notion of justice. After a short discussion of some main characters of the present worldwide crisis of the classical liberal model, I present two main theories of justice as fairness. John Rawls' theory in political philosophy that emphasizes how really equitable judgements must overcome the equalitarianism of the Classical Liberalism, by considering the real possibilities of individuals and groups of accessing and enjoying commodities and utilities, as well as, the "basic liberties" defining the citizen equal dignity in the Modern State. Rawls propose, therefore, a notion of fairness compliant with the Kantian normativism, and a notion of fair distributive justice based on the ethical principle of the maximin, as a criterion for judging the righteousness of the State Institutions. The other theory of justice as fairness I discuss in this paper is an evolution of Rawls' in the direction of the development of a "comparative distributive justice", without any normativism. This theory is developed in the context of the newborn discipline of the "social choice theory", formalizing social decision processes, with applications in economic, social, and political sciences. What characterizes Sen's theory is its original synthesis between the Aristotelian notion of fairness, based on the "personal flourishing", and Adam Smith's ethical principle of the "extended sympathy", by which making comparable different approaches to pursue the personal flourishing, i.e., for achieving "valued and valuable ways of being and of doing", compliant with, and respectful of, different value systems.
\end{abstract}

Keywords: justice as fairness; distributive justice; social choice theory

\section{Introduction}

\subsection{The Crisis of the Liberalist Vision of Society and Democracy}

In the recent years, we observe an exponential growth at all levels of the worldwide debate in social, political, and economical sciences about the future of our society, and about the same democratic order of our institutions. All this depends on the evident crisis of the classical liberalist vision that supported the modern vision of economy, society, and democracy, as well as their strict relationships in the Western Tradition ${ }^{1}$. This crisis has essentially two strictly related roots, cultural and socio-economical:

1. The irresistible rise in the world economic and political scenario of countries and societies-think only of China, India, and the Islamic countries of the oil economy-that never knew the

1 By crisis of the liberal vision, we mean the failure to achieve the goal of protecting the individual considered simply as a juridical moment of the state. Furthermore, the liberal economic vision, born in the sense of the liberal vision, claims to adopt only the econometric keys to measure the value of man. 
Enlightenment movement in their history, which is the proper culture medium in which the liberalist principles in economy and in politics grew up in Western countries. Paradoxically, just the lack of a strong and diffused culture of democracy, and of defense of the rights of the individuals and of the populations, gave these countries and their economies an undue advantage in the global markets as far as still being ruled by liberalist principles.

2. The actual crisis on a worldwide dimension of the global economy, ignited by the financial crisis of 2008, and strengthened by the Covid-19 pandemic crisis, determined a diffused impoverishment of the populations in all countries ${ }^{2}$, with evident problems for their inner social, political, and even institutional stability, as well as of the whole economical system. This crisis implied, on the one hand, a diffusion of populistic and nationalistic movements, substituting democracy with demagogy. On the other hand, for stemming these phenomena, the actual crisis determined a renewed massive intervention of the State in the economy. All this requires a complete revision of the relationship between the public and the private spheres in economy and society with respect to the classic liberalist dogmas. Therefore, the economists are today the first ones in recognizing that the actual crisis requires a deep revision of the relationship between economy and the personal "welfare" — and more extensively, the personal "well-being"—of individuals and groups in our societies, putting newly and explicitly the economical science and practice at the service of the common good [1]. This revision must necessarily include a suitable redefinition of the indices of economic development-starting from the notorious GDP-that must take into account much more factors, the environmental factors before all, on which a proper and more realistic measure of the social and economic development of a given country depends [2].

Finally, not only the just recalled and dramatic ecologic challenge, but another world-wide phenomenon is acting as an impressive "enzymatic factor" of the actual crisis of the modern model of society, economy, and democracy with which we are acquainted. This phenomenon is the actual information and automation revolution characterizing our "Communication Age". This is deeply influencing our economic, social, and political lives along three main lines:

1. From the economic standpoint. A first factor is surely the redefinition of the job market, because the development of automation and robotics will imply certainly, not only the creation of new jobs related to the acquisition of middle-high computational skills and competences by the workers, but also with the loss of low-skill, lower-wage jobs in the realms of manufacturing and of services for less educated workers. This process of substantial change of the job-market will influence, and partly is already influencing in a decisive way, our society, even though the different studies disagree in calculating and predicting the effective percentages of the job gain/loss determined by the automation [3]. Finally, this process had a substantial acceleration during 2020 for the sudden increase of so-called "smart-working" because of the Covid-19 crisis. Anyway, all this is emphasizing and will emphasize ever more in the next decades the divide between richer and poorer layers of populations, mainly depending on the continuous education factor for the new skill acquisition in computer science (our "Communication Age" is in this sense a "Knowledge

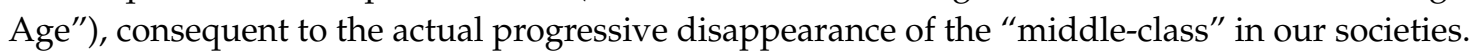

2. From the social standpoint. The necessary support of AI systems for human decision making in many realms of our social, economic, and financial activities, public and private policy maker decisions included, is another factor deeply changing our societal structure. Because this support is in many senses unavoidable, for the complexity of the scenarios, and for the necessary velocity of the decisions to perform in it, this ever growing interaction in our Communication Age between

2 https://www.cisl.it/grandi-temi/europa-mondo-politiche-migratorie/4539-rapporto-oxfam-un-economia-per-il-99-a-fron te-dell-1-piu-ricco-della-popolazione-mondiale-i-dati-sulla-poverta-e-la-distribuzione-della-ricchezza-nel-mondo-unfocus-sulla-distribuzione-della-ricchezza.html; https:/www.econopoly.ilsole24ore.com/2019/12/02/poverta-nel-mondo/? refresh_ce=1; https://www.indexmundi.com/facts/indicators/SI.POV.GINI. 
the "conscious communication agents" (humans) and "unconscious communication agents" (machines) is effectively working for the constitution of a "collective intelligence", integrating the natural and the artificial ones [4]. Therefore, this tumultuous development of the AI support in the "big data" management, underlying the decision processes in any realm of our social, economic, and (hopefully) political lives, is igniting a worldwide debate about the many consequent ethical issues implied. Indeed, a growing awareness is emerging among scholars that the "machine learning" in AI systems is not at all ethically neutral. In fact, the different models in the automatic statistical aggregation of the variables-mathematically determining the "degrees of freedom", and/or the "orthogonal dimensions" of the representation space of the model—on which any "learning process" (automated or not) in statistical sciences ultimately consists, deeply influences the automated decision process in AI systems. This can often determine unintended but real "algorithmic injustices", whereas AI systems are involved in decision processes deeply influencing the people lives. Namely, when they are involved in social choice processes $[5,6]$. This opens the way to a new exciting research program for the development of ethically "good algorithms" [7-9] in AI, requiring the multidisciplinary collaboration of computer scientists with social, moral, and law philosophers and scholars, in the common realm of the formal(ized) philosophy (formal ontology, formal epistemology, formal ethics, formal social choice theory ... ) [10-12].

3. From the political standpoint. Finally, the internet revolution in our Communication Age is deeply changing another pillar of the modern democracy: The public discussion, in which the different opinions and positions might confront each other, in order to properly inform public opinions. As I discussed at length elsewhere [13,14], because of the internet, politics is moving from the "public squares" of our cities [15] to the "public domains" of the world wide web, with the impelling risk of transforming the public dialogue-an unavoidable instrument of democracy-into a dangerous tool of consensus manipulation by hidden powers. Indeed, by the uncontrolled diffusion of "fake news" using the "likes" of millions of virtual avatars enduring only the few seconds necessary to make "viral" whichever message, news, and images on the computers and smartphones of million people all over the world, the machine of political propaganda has today an instrument of unprecedented power. This is systematically used by undisclosed inner and foreign powers for manipulating the minds of unaware citizens, distorting elections, polls, and then the democratic life of nations and peoples. At the same time, such a "dictatorship of polls" is transforming the policy makers and their decisions into as many hostages of such a doped consensus based on the immediate (apparent) results. This makes governments ever more unable to pursue the common good, generally linked to the pursuing of long-term results, jeopardizing the same notion and practice of a genuine representative democracy. All this has led some political philosophers to speak about the necessity of substituting the old model of representative democracy with the new one of direct democracy or e-democracy, based on the continuous consultancy of citizens via internet. Particularly—sometimes invoking an improbable relationship with Athens' direct democracy - they vindicate the better transparency that this form of democracy would grant with respect to the modern representative model corrupted by the growing influence of the economical lobbies [16]. Despite its youth, this proposal appears today already old, overall because its claim for a better transparency of the political debate that the internet usage would grant, appears today evidently disproved by the many facts of the consensus manipulation practiced via the internet in many countries, and not only during election periods. Nevertheless, it is evident that the "virtual public square" of the internet is today a fundamental place where exerting the "public discussion" as far as the net is adequately safeguarded. That is,

a. As far as international and academic institutions, as it is happening today, are appointed to apply a rigorous fact-checking to the news diffused on the net, and more generally, 
b. As far as national and international institutions watch efficaciously over the net, in a controlled collaboration with the internet service providers (ISPs), for granting the privacy and the fighting against any fraudulent usage.

On this regard, some scholars refer to the notion of deliberative democracy developed by Jürgen Habermas, correcting the "representative democracy" into a "two-track model in which representative democracy is backed by the public sphere and a developing civil society" [17]. Because the normative concept of the "public sphere" supposes "the uncoerced communication of equal participants with equal access and equal rights to intervene or propose themes", it is evident that an internet safeguarded against its fraudulent usage, "could fit into this concept of public sphere and influence the quality of political debates, and emphasizes the important role it can play in the political process" ([17], p. 31). As we see below (see Section 3.2), more recently, Amartya Sen, even though without referring to Habermas, but, on the contrary, emphasizing the necessity of a rigorous "fact-checking" and of a tireless fight against any frauds, shares the same conviction of the fundamental role of the internet for promoting efficaciously the public discussion in a "participative democracy". This must be centered on the rights and the needs of the persons, and on the fair development of their capabilities, in the context of his approach to the "social choice theory" (SCT) — of which Sen is one of its pioneers-based on his revolutionary idea of "a comparative distributive justice" (see [18] and [19], pp. 453-472).

\subsection{The Scheme of the Present Contribution}

In a previous work, I emphasized the essentially convergent contributions that three scholars of the 20th century, John Rawls, Amartya Sen, and Luigi Sturzo, gave to a reform of the political and economic liberalism [20]. On the contrary, in the present paper, I limit myself to an examination of the first two of them: John Rawls and Amartya Sen. These scholars can help to solve many of the components of the actual crisis of the Classical Liberalism I sketched before, because in many senses, they theoretically anticipated them. Unfortunately, at the same time, the corrections of the Liberalism they suggested are today often forgotten by politicians and policy makers, also because the thought of these scholars is not sufficiently known by the public. Or, if we prefer, their contributions are not sufficiently represented in the contemporary "public discussion" about the present and the future of our economy, society, and democracy.

In this paper, I illustrate, from the standpoint of the political philosopher, some essential and then significant aspects of their intellectual production and personal testimony, sufficient however to depict some common, convergent lines of solutions of the actual crisis. This convergence is much more significant because they start from quite different perspectives, interests, cultural, and educational backgrounds, even though united in the desire of supporting, correcting, and improving the modern form of economy, society, and democracy, against any form of political and ideological totalitarianism.

In Section 2 of this paper, I illustrate therefore some fundamental components of the liberalist theory of John Rawls (1921-2002), characterized by the introduction into the "public sphere" of the economic, social, and political justice-as distinguished from the "private sphere" of the personal and moral good-a fairness criterion for an equitable distribution and access to the "fundamental liberties" (or "primary goods" as Rawls defined it), and then to the economical commodities, assets, and opportunities. Because Rawls is a political philosopher, and his aim is to construct a theory of Righteous Institutions, he introduces as fundamental fairness criterion his famous maximin principle. That is, a just Institution in the State is the Institution granting the maximum of the (economic but also social, cultural, educational, ... ) resources to the less advantaged individuals and groups, because effectively they are availing themselves of the minimum of these resources. As we see, for this aim, Rawls introduced in his theory of justice as fairness the hypothetical, abstract notion of the original position - as distinguished from the notion of the "state of nature" of the other social contract theories of the classical Liberal Tradition-to which the political institutions and the political actors must refer in their political choices. Therefore, for granting a fair distribution of commodities and resources, 
the righteous Institutions of a State must grant that the choices must be taken from behind a veil of ignorance about the social, economic, ethnic, sexual, ... , but also moral and religious differences, and the relative opposed interests, so to constrain parties and policy makers to make equitable choices from the fair perspective of all members of the society-from the worst-off to the best-off members.

In Section 3 of this contribution, I discuss a further development of the liberal position based on the notion of "justice as fairness" introduced by Rawls in the contemporary debate. This development evolved Rawls' notion of the "distributive justice", as an essential correction of the classical liberalism, into the revolutionary notion of the "comparative distributive justice". This improvement was developed by a former student, and then collaborator and colleague of Rawls, at the University of Harvard: the Indian economist and Nobel Laureate (1998) Amartya Sen (1933-). What characterizes Sen's notion of "justice as fairness" as to Rawls" is the overcoming of the abstract character of Rawls' notion of justice, by emphasizing another possible path of evolution of the liberal thought, different from the transcendentalist one, leading from Kant to Rawls' "original position". As we see, this alternative path uses an idea of another champion of the Liberal Tradition, Adam Smith, an idea that is not sufficiently developed during the Modern Age. Namely, Smith's principle of "extended sympathy", discussed in his book Theory of Moral Sentiments. This principle consists, in the capacity of "putting oneself in the position of the other", as the foundation of the "detached observer" in ethics, and of the "equitable judgments" in jurisprudence.

What is absolutely relevant in Sen's approach is that he gave an axiomatic version, in the context of the formal SCT, of Smith's principle of extended sympathy that is the core of Sen's revolutionary quantitative theory of justice as fairness based on a comparative approach to the "distributive justice". In other terms, it is not necessary to refer to some absolute because abstract criterion of fairness like in the normativism of Rawls' purely hypothetical "original position" for granting equitable judgments in social, economic, and political sciences. Indeed, by the formalization of the "extended sympathy" principle in SCT, we are able to consider in our equitable social assessment the different tastes as well, and even the different moral and religious values of whichever finite number $n$ of persons and groups. This possibility is fundamental in our pluralistic and global culture and society, where "global problems require local solutions" for being possible and effective. All this is the basis of the human-centered or personalistic approach of Sen to economics, derived by his original synthesis between Aristotle's and Smith's approaches to justice as fairness. With respect to the classical utilitarian approach to economic ethics in the Liberal Tradition, Sen's personalistic approach considers, indeed, the enjoyment of economic commodities and utilities not as ends, but as means for reaching the goal of personal flourishing. That is, for the concrete realization of the personal capabilities into valued functioning's, i.e., valued "ways of doing and being" considered desirable by a person, according to her personal value system. In other terms, differently from the Liberal Dogma, not the individuals but the persons as individuals-in-relationship, with their natural and social environments, are the main economical, and then political and social actors in Sen's theory.

Finally, in Section 4, I resume the main suggestions that Rawls and Sen are able to give to some relevant points of crisis of the liberal vision of politics, society, and economy discussed in the introductory Section 1 of this paper. They pursued this shared program of correction and improvement of the liberal and democratic vision of our society and economy from the different standpoints of a political philosopher and of an economist. Nevertheless, both of them converge in proposing to correct the classical liberal vision of the justice in politics and economy by a theory of justice as fairness (distributive justice) based on the maximin ethical criterion, both for the political Institutions of the State (Rawls), and for SCT in the social decision procedures in society, politics, and economics (Sen). Particularly, in Sen's vision, the notion of comparative distributive justice allows for the depiction of social decision procedures respectful, by the usage of the ethical "extended sympathy" principle, of the different value systems of persons and groups, and then respectful of the different strategies for pursuing some shared ranking of preferences for welfare (well-being) social states, in which any social choice procedure ultimately consists. Therefore, it became a concrete implementation of the 
"extended sympathy" principle the open support given by Sen to Pope Francis and his encyclic Laudato sì (2015)—the "ecological encyclic" of the Catholic Church that puts on a complementary plan the "natural" and the "human" ecology. This "extended sympathy" is reciprocated by the invitation to Sen from the Catholic Church for being-together with the Bangladeshi entrepreneur and economist Muhammad Yunus, Nobel Peace Prize (2006) - a keynote speaker at the World Conference: "The Economy of Francesco", organized (effectively re-scheduled because of the Covid-19) for 19-21 November 2020 in Assisi (Italy), the city of St. Francis (https://francescoeconomy.org/). On the other hand, there exists in literature a widely recognized convergence between Sen's personalistic vision of economy versus the individualistic vision of liberalism, and the personalistic vision in economy defended by the Social Doctrine of the Catholic Church. We discuss briefly this point in the Conclusions of this paper.

\section{The New Liberalism of John Rawls}

\subsection{A New Theory of the Social Contract: Justice as Fairness}

The topic of justice had several interpretations during the centuries in the Western Philosophy since Plato defined the Idea of Justice in the eighth book of his Republic Dialogue [21]. Among the most significant modern interpreters of Plato's notion of justice is surely the American Philosopher John Rawls (1921-2002). This professor of Harvard influenced in a decisive way the contemporary reflection on the theme of justice in the political philosophy, since the publication of his first masterpiece $A$ Theory of Justice in 1971 [22]. As Robert Nozick stated on this regard: "political philosophers now must either work within Rawls' theory or explain why not" ([23], p. 183).

What characterizes Rawls' theory of justice is the recognition of "the fact of pluralism" that, with the globalization characterizing our society, represents the coexistence of several cultures, identities, and inclinations which persons and groups have on the basis of different origins and experiences, so to give a concrete implementation to the freedom of thought.

The fact of pluralism poses the challenge to the political philosopher of how is it possible to find a meaning of the term "justice" able to represent all the citizens politically. For this reason, Rawls develops during all his career a particular form of "political liberalism" that recalls us directly the title of his second masterpiece, published in 1993, The Political Liberalism [24]. What characterizes Rawls' approach to liberalism is that it must formulate and defend in the "public square" ([15], pp. 249-271) of politics and of institutions not only the rights and the goods of all citizens on the basis of an abstract egalitarianism, but also and before all their fair distribution.

Already Immanuel Kant—an author to whom Rawls is largely indebted-in his famous essay $A n$ answer to the question: What is enlightenment? [25], published for the first time in 1784 on the journal Berlinische Monatsschrift (Berlin Monthly), distinguished between the "public reason" (public sphere) and the "private reason" (private sphere) of an individual in society. The freedom is, of course, a necessary condition for the possibility that each citizen abandons her/his state of political "minor age", becoming aware of her/his role in the politics of a given country. With Kant, therefore, a tradition starts characterizing all the modern liberal thinkers, having its contemporary apex in Rawls' thought.

Unfortunately, this freedom, ever more desired and pursued by the modern citizen, often transformed itself into an occasion of countless social, cultural, and finally religious conflicts. The reason is that the political representatives, either individual or collective, pretend to occupy the public positions and institutions by imposing to everybody their own vision of justice, without taking into account the plurality of the positions in the society that they ought to represent and to defend. The pioneering attempt of Rawls consists in formulating a theory of justice separating the private from the public realm, and then what is "right" from what is "good" in an original unprecedented way.

For this aim, Rawls develops his famous thought experiment of the original position, replacing the "state of nature" of the classical social contract philosophers, such as Thomas Hobbes, Jean-Jacques Rousseau, or John Locke. The hypothetical original position is aimed at connoting which principles of justice must characterize a society based on the free and fair cooperation among citizens, including the 
respect for liberty, and for reciprocity $[22,26]$. There are therefore two principles of justice distinguishing the original position ([22], p. 266):

First Principle: Each person is to have an equal right to the most extensive total system of equal basic liberties compatible with a similar system of liberty for all. Second Principle: Social and economic inequalities are to be arranged so that they are both: (a) To the greatest benefit of the least advantaged, consistent with the just savings principle, and (b) attached to offices and positions open to all under conditions of fair equality of opportunity.

In other terms:

1. The first principle assigns an absolute priority to liberty in whichever form, under the condition that this first principle can be limited only by the defense of the same liberty.

2. The second principle defines the basket of commodities to be distributed according to the fairness criterion of the maximin. That is, by assigning more resources to the less advantaged individuals and groups in the society, to level the inequalities derived from "the natural lottery" that blindly distributes talents and resources under condition of fair equality of opportunity.

It is, therefore, in this second sense of justice that Rawls' original position is different from the "state of nature" of the classical social contract theories. The original position is indeed a hypothetical situation of "original equity" among all citizens. It has never historically happened, but just for this reason it can work as a normative criterion in some sense absolute, to which the pluralism of the different historical positions on justice might refer.

For defining a new social contract based on the original position, Rawls introduces therefore another characterizing notion: The parties must select the basic structure of the society they will live in, behind a voluntary veil of ignorance. That is, they must operate their choices voluntarily ignoring their present and future distinguishing characteristics - their ethnicity, social status, gender, . . , and overall, their different moral and religious beliefs-in order to choose the principles of the new social contract impartially and rationally. More recently, Maxcy J. Spencer so synthesized Rawls' notion of the veil of ignorance

Imagine that you have set for yourself the task of developing a totally new social contract for today's society. How could you do so fairly? Although you could never actually eliminate all of your personal biases and prejudices, you would need to take steps at least to minimize them. Rawls suggests that you imagine yourself in an original position behind a veil of ignorance. Behind this veil, you know nothing of yourself and your natural abilities, or your position in society. You know nothing of your sex, race, nationality, or individual tastes. Behind such a veil of ignorance all individuals are simply specified as rational, free, and morally equal beings. ([27], p. 93)

As Rawls put it, from behind the veil of ignorance, "no one knows his place in society, his class position, or social status; nor does he know his fortune in the distribution of natural assets and abilities, his intelligence and strength and the like" ([22], p. 118), so that the original position is essentially a position of "original fairness" among all citizens serving as abstract universal criterion for equitable political and economic choices.

\subsection{Individual and Collective Freedom and the Role of Institutions}

The liberalism of Rawls is then atypical because his thought and procedural experiment of the original position gives a social character to his political theory, since the fair distribution of commodities is for him the necessary condition for enjoying political rights. Only a citizen sufficiently enjoying her/his social rights can exert her/his civil and political rights. In other words, Rawls, by separating "the right" from "the good", tries to individuate a universal formal principle allowing justice to acquire the character of fairness, not by assigning to all the same quantity of commodities, but their relative 
quantities, progressively adequate to the situation of maximal need of the worst-off people in the society. This task of a fair distribution is the proper task of the institutions, defined by Rawls as the basic structure, which cannot follow any particular conception of the good, because their proper nature is the safeguard of all the members of a society.

This paradigm of "institutional neutrality" follows therefore in an original way the Liberal Tradition, requiring that a citizen must be free from any intrusion of the State, and of the Society in general. At the same time, Rawls' liberalism is mitigated by his social principle of the distributive justice, inaugurating a new form of political liberalism, animated by a new principle of deliberation form: The reasonable. He, indeed, distinguishes between "the rational", and "the reasonable", because of the necessity of the political actors, as far as subjects endowed with ratiocination, of surrendering rationally their own convictions-defined by Rawls as comprehensive-when they enter "the public square".

Therefore, the conditional clause posed by Rawls to the political representativeness is that each policy maker can surrender her/his own opinions, the religious convictions included, if all the other actors make the same choice. The political process would produce in such a way the norms to be taken, by a continuous confrontation defined as consensus by intersection, for enlarging as much as possible the coverage of the political representativeness in a society. Normally, in the Liberal Tradition, such a neutrality is made coincident with the expulsion from the public square of whichever form of religion that, as far as dogmatic, cannot be submitted in principle to the scrutiny of the reason. On the contrary, Rawls' liberalism—sharing on this delicate point the same position anticipated by Luigi Sturzo, as we discuss below, even though Rawls did not know the work of this Italian politician and philosopher-does not pretend the abandoning of a given faith by the politician, but the abandoning of its "comprehensive" character. In other terms, it is mandatory in Rawls' liberal theory that the believing politician accepts, because of the pluralism, her/his responsibility of translating some socially useful contents of his own faith - that for him and only for him is a comprehensive doctrine-into political, reasonable terms, so to make them acceptable by all, or, at least, by the great majority of the political actors.

A much more constructive and effective approach toward the different value systems of comprehensive doctrines such as philosophies and religions in a pluralistic society like ours characterizes the revolutionary theory of Amartya Sen of a "comparative distributive justice"3. Our society, indeed, is particularly in need of a reconciliation between economy, politics, and ethics, for the deep economic, political, and social crisis with which is faced.

\section{The Comparative Notion of Distributive Justice in Amartya Sen}

\subsection{From the Political Philosophy to the Social Choice Theory}

The motivation for awarding Amartya Sen (1933-) in 1998 with the Nobel Prize in Economic Sciences was "for his contributions to welfare economics" and, more specifically, for his "research on fundamental problems in welfare economics, his studies of social choice, welfare measurement, and poverty" [28]. However, Sen chose to completely dedicate his Nobel Lecture, "The Possibility of Social Choice" [29], to the illustration of the newborn discipline of the modern social choice theory (SCT) of which he was effectively a pioneer together with another Nobel Prize in Economic Sciences (1972): Kenneth Arrow, one of the greatest representatives of the "neoclassical economy school". As Sen explains in his lecture,

The Royal Swedish Academy of Sciences referred to "welfare economics" as the general field of my work for which the award was given, and separated out three particular areas:

3 As Sen himself highlighted Rawls's attempt to find the highest form of equity in a complex pluralism led, through the veil of ignorance, to annihilate any plural difference as a conditional clause in a situation of fair reciprocity. His transcendentalist institutionalism thus thins the citizen's ethos too much in favor of institutional "rightness". See my Libertà Giustizia e Sviluppo. Sturzo, Rawls e Sen: Un dialogo inaspettato (Solfanelli Editore, Chieti 2020). 
social choice, distribution, and poverty. While I have indeed been occupied, in various ways, with these different subjects, it is social choice theory, pioneeringly formulated in its modern form by Arrow (1951) [30], that provides a general approach to the evaluation of, and choice over, alternative social possibilities (including inter alia the assessment of social welfare, inequality, and poverty). This I take to be reason enough for primarily concentrating on social choice theory in this Nobel lecture. ([29] p. 179)

The centrality of the SCT for the economic, social, and political sciences is immediately evident when we reflect over its "formal object", that is, over the fundamental problem at issue in this discipline. Indeed,

it includes within its capacious frame various problems with the common feature of relating social judgments and group decisions to the views and interests of the individuals who make up the society or the group. If there is a central question that can be seen as the motivating issue that inspires social choice theory, it is this: how can it be possible to arrive at cogent aggregative judgments about the society (for example, about "social welfare", or "the public interest", or "aggregate poverty"), given the diversity of preferences, concerns, and predicaments of the different individuals within the society? How can we find any rational basis for making such aggregative judgements as "the society prefers this to that" or "the society should choose this over that" or "this is socially right"? ([29] p. 178)

SCT is therefore a discipline covering a variety of distinct issues, many of them were the objects of Sen's research work and are all of a straightforward relevance and actuality, e.g., in political sciences, on which conditions would the majority rule yield to unambiguous and consistent choices? More generally, on which conditions can we say that a society as a whole is doing something, despite the different interests of its members? More deeply, on which conditions can we accommodate rights and liberties of individuals and groups in a society, giving at the same time an adequate recognition to their different preferences, often inspired by different value systems?

In social and economic sciences, a typical problem at issue is how can we define measurements of aggregate poverty, and attribute consistently them to different groups of a given population? Finally, "how do we appraise social valuations of public goods such as the natural environment, or the epidemiological security?" ([29] p. 179).

The SCT, in its broadest sense, has ancient roots, arriving until Aristotle's book of Politics in the Western Tradition, or Kautilia's book of Economics in the Eastern (Indian) Tradition, both of the 4th century B. C., and both inspiring Sen's work. In the Modern Age, during the European Enlightenment at the end of the 17th century, this discipline has one of its pioneers in Marquis de Condorcet, who first applied the statistical analysis to social sciences arriving at his famous "paradox of voting" [31]. Nevertheless, the contemporary approach of Arrow and Sen to SCT is the extension to this discipline of the axiomatic method of formal logic. In this way, they transformed it into a branch of formal philosophy, effectively the "formal social philosophy" [10-12], as I anticipated in the Introduction. In this formal sense, the definition of SCT emphasizes that the core of the methodology consists in defining a suitable aggregation criterion, which is different for the different contexts of application, of the individual preferences/choices into a single collective preference/choice "that adequately reflects 'the will of the people'" ([32], p. 133).

However, along all his career, Sen emphasizes a fundamental methodological caveat against any "idolatry" of the formalization in SCT. That is, the necessity of a complementary usage of the formal mathematical methods and of the informal reasoning. Indeed, if it is true that some fundamental results in SCT could not be obtained without the usage of formal reasoning-before all, the momentous Arrow's "impossibility theorem" with Sen's solution in SCT-it is also true that a "widespread public communication is crucial for the use of SCT", because the same social and political relevance of 
SCT "calls simultaneously for formal investigation and accessible scrutiny" ([28], p. 184) for a public discussion of SCT analyses and results ${ }^{4}$.

Anyway, the pioneering formulation of SCT by Arrow consisted in the formal formulation of a "social welfare function", intended as a function ranking (ordering) social states as less, more, or indifferently desirable with respect to individual welfare preferences [30]. What is fundamental is that for the first time, Arrow formalized axiomatically his theory, by introducing as axioms very reasonable conditions for any social choice-“"mild-looking conditions", Sen defined them—such as:

1. Unrestricted domain, i.e., the social preferences must constitute a complete ordering, covering any possible set of individual preferences.

2. Pareto efficiency or "unanimity", i.e., all individual orderings have the same possibility of determining the social ordering.

3. Independence of irrelevant alternatives, i.e., the social choice over any set of alternatives must depend only on those alternatives.

4. Non-dictatorship, i.e., there must be no individual ranking of preferences imposing itself as valid for all.

The formal result, known as the "Arrow impossibility theorem" [30], is that there is no social welfare function-and more generally, no social choice function-that can satisfy simultaneously all these four conditions. Particularly, conditions 2 and 4 have incompatible results. That is, given condition 2, for any possible individual ordering, there must be a "pivotal" individual preference ranking that orders the alternatives. Arrow's theorem aroused immediately a strong interest and generated, and is also generating more recently, a wide literature in answer to it, including the demonstration in SCT of many other similar impossibility results, in a large family of applications ${ }^{5}$. If only dictatorship would avoid inconsistencies, the consequences are evident in politics for a participatory and representative democracy based on the aggregation principle of majority in voting. Similarly, in welfare economics, this would signify "a gross inability to be sensitive to the heterogeneous interests of a diverse population". In conclusion, it seems that the "social appraisals, welfare economic calculations, and evaluative statistics have to be inevitably arbitrary or irremediably despotic" ([29], p. 181).

For immediately understanding the concrete- that is, scientific in the Galilean sense of science, mathematically formulated and empirically measurable-of Sen's appraisal of the impossibility theorems in SCT, think only at the different forms of "dictatorship" by some elites in economy (multinational companies, multinational financial firms, multinational banks, etc.), and in the ever more strictly related communication field of the "internet service providers" (ISPs). They are today effectively reduced to only three "monopolists of the web" all over the world, with a capitalization outclassing not only any other company in the capital market, but also the national budgets of a large part of countries all over the world. These forms of effective "dictatorship" in the SCT sense (one "pivotal" ranking of preferences jeopardizing all the others), depends on the fact that both economy and internet are governed following Pareto's "liberal" axiom of an abstract egalitarianism of the classical Liberalist Tradition, not corrected by concrete fairness criteria. Think only of the great difficulties to impose an equitable taxation to the multinational entities governing the economy, the "web monopolists" included. More recently, think of the necessity of correcting the criteria of the "rating agencies" in judging the debt of nations and companies, toward an equitable direction, taking into account the sudden growth of their borrowing because of the 2020 pandemic disaster.

4 Effectively, Sen's main monograph in SCT, Collective Choice and Social Welfare, both in its first edition of 1971 [18], and in its second expanded edition of 2017 [19], alternated between "starred" chapters with formal analysis, and "non-starred" chapters with informal discussion.

5 For immediately realizing the scientific impact of Arrow's Theorem, it is sufficient to consult the long list of publications related to it in 1998 ([29], p. 181), and updated in 2017 in ([19], pp. 491-566). 
Indeed, the significant contribution given by Sen to the development of the newborn formal SCT that the impossibility theorems seemed "to have killed in its cradle" is essentially twofold:

1. Firstly, he demonstrated formally that the impossibility results can be avoided if we drop the "Pareto unanimity condition" (Arrow's Axiom 2) of an abstract egalitarianism in determining the social choices for all the individuals and groups composing a society, because it is evidently an unrealistic condition. In a word, using the title of one of the Sen papers, the impossibility theorems in SCT demonstrates effectively the "impossibility of a Paretian liberal" [33]. This means, the necessity for any consistent theory of the social choices of introducing in SCT fairness conditions of interactive comparison among persons and groups for their effective access/enjoyment of fundamental liberties and/or of economic commodities and utilities that today include also communication utilities.

2. Secondly, the necessity of introducing in the SCT formalism some fairness quantitative criteria transformed Arrow's original "social welfare functions" - which work on preference rankings and then on "ordinal numbers"-into "social welfare functionals" defined on "cardinal numbers", because measuring some economic or social statistical magnitudes. Some of these fairness quantitative criteria introduced by Sen in welfare economics-main objects of the two editions of his monograph on SCT $[18,19]$ - are the interpersonal comparison of commodities and utilities, or the statistical comparative evaluations of the effective access of persons and groups to what Rawls defined as "the fundamental goods" [22,26], the fundamental rights and liberties included.

\subsection{From Institutions to Persons in Economy and Politics}

What characterizes Sen's theory of "justice as fairness" as to Rawls' one that originally inspired him [34], as well as to the utilitarian theories of the classical liberalism [35], is well synthesized in the following passage

In recent years there has been considerable discussion on an approach to justice that concentrates on people's capability to lead the kind of life they have reason to value-the things that they can do, or they can be. The roots of the approach can be traced to the ideas of Aristotle, and, to some extent, Adam Smith; it concentrates on the opportunities that people have to lead valuable and valued lives. Aristotle saw this achievement in terms of 'human flourishing'. Among other things, he pointed out, in Nicomachean Ethics, that wealth 'is evidently not the good we are seeking' - 'for it is merely useful for something else'. ([19], p. 356)

To sum up, with respect to the classical utilitarian theories, Sen's theory of justice considers economic commodities and utilities not as ends but as means for people, in order to reach the goal of their "personal flourishing", interpreted as the concrete opportunity for people "to lead valuable and valued lives" on the basis also of their own systems of values/preferences. On the other hand, with respect to Rawls' reference to one only abstract fairness condition that is equal for all citizens because, based on the voluntary oblivion of the personal differences in the "original position", Sen vindicates the necessity of referring to individual functioning's and capabilities for speaking about "a personal achieved life".

A personal achieved life can be seen as a combination of "functioning's" (i.e., of doings and beings), and, taken together, can be the basis for assessing that person's quality of life. The functioning's on which human flourishing depends include such elementary things as being alive, being well-nourished and in good health, moving about freely, and so on. It can also include more complex functioning's, such as having self-respect and respect of others, and taking part in the life of the community (including 'appearing in public without shame'), on which Adam Smith in particular presented an extraordinarily insightful analysis in his Wealth of Nations. ([19], p. 357)

On the other hand, "personal capabilities" consist 
in the set of combinations of functioning's from which the person can choose any one combination. Thus, the "capability set" stands for the actual freedom of choice a person has over the alternative lives that he or she can lead. ([19], p. 357)

For our aims of suggesting effective corrections of the actual crisis of the liberal vision in economic and social sciences, and of the consequent crisis of the liberal model of representative democracies in politics, it is very useful to follow Sen in his comparison between Rawls' notion of distributive justice in political philosophy, and his own revolutionary notion of comparative distributive justice in SCT appliable in economic, social, and political decision processes, based on "functioning's and capabilities" of different persons and groups in the society ${ }^{6}$.

In his reconstruction of Rawls' theory, Sen refers to Rawls' "Two Principles" of his theory of justice as fairness shortly discussed before at the end of Section 2, by using his schematic approach to whichever social theory of justice, characterized by the two notions of the basal space (i.e., the collection of variables to which the assessment of justice is sensible under that theory), and of the aggregation system (i.e., the discriminating principle among the basal variables for the justice assessment), characterizing different social theories of justice ([19], ch. A3, p. 337ff.) ${ }^{7}$. Effectively, in this framework, Rawls' "First Principle" determines, according to Sen's analysis ([19], p. 348ff.) the basal space of his theory. That is, the main variables characterizing Rawls' theory of justice, constituted essentially by the "basic liberties" in reference to the "primary goods" that "citizen need as free and equal persons, and claims to these goods are counted as appropriate claims" ([36], p. 257), because they are things "that every rational man is presumed to want". On the contrary, Rawls' "Second Principle" according to Sen's analysis constitutes the aggregation principle of the main variables of the theory, and it is essentially the maximin criterion of Rawls' notion of fairness, because it requires that "social inequalities be arranged to make the worst-off best-off".

Therefore, if we compare Sen's theory of justice as fairness with the Rawlsian one, it is evident that the basal space of Sen's theory is constituted by the set of "functioning's and capabilities" characterizing the different persons and groups of persons in a society, and on which the fair justice assessments of the social states must be based in Sen's theory of the "personal flourishing". This flourishing surely includes the "basic liberties" and the "primary goods" of Rawls' "original position". However, the personal differences are not hidden behind any ascetical "veil of ignorance". Both the differences derived by the value systems of persons and groups, and overall, the differences derived by the "manifest injustices and inequalities" in the resources and opportunities distribution, constitute the unavoidable starting point of a fair assessment of justice in Sen's theory.

What, then, as to the "maximin criterion" constituting the discriminating (variable aggregation) principle for evaluating the righteousness of the Institutions in Rawls theory? Sen emphasizes that in principle Rawls' maximin criterion could be used also in SCT for ordering social states based on individual welfare preferences, in order to obtain a complete social ordering ([19], p. 193).

For instance, for any social state, we may order the individuals in terms of their welfare and pick on the worst-off individual. This can be compared with the welfare of the worst-off individual in another social state, and so on, so to have recursively, at least in principle, a complete social ordering. ([12], p. 106)

However, Sen demonstrates that this is not formally true in practice. Indeed, the maximin criterion in Rawls' absolute and non-contextual interpretation, is not compatible, neither with Arrow's "social

6 In this comparison, I refer also to [12] that is particularly useful for our aims.

7 For instance ([19], pp. 339-340), in the utilitarian theories of justice, the "basal space" consists "in the combination of the utilities of the different individuals, and nothing else-rights, freedoms, opportunities, equal treatments—is valued except for instrumental reasons". Consequently, the "aggregation principle", discriminating between just and unjust states in such theories is the simple "utility sum-total" for assessing the social state ("sum-ranking"), without taking into account other relevant factors, such as measures of "dispersion" and/or of "inequality", etc. 
welfare functions", nor more generally with any "collective choice rule" where different individual preference rankings coexist ([19], pp. 193-194). Effectively, Sen gives us an impressive list of the main limitations that the maximin principle has in its Rawlsian absolute interpretation, if taken uncritically as a decision rule in social choices ([19], pp. 195-198),

as unfortunately it has been done too many times by policy makers, and in recent times, by the so-called "populist movements". Indeed, if it is absolutized as a decision rule in social choices, the maximin criterion easily becomes a factor of social injustice and economical regression, given that it oversimplifies complex situations. And effectively, it is often accompanied by misinformation campaigns on the media, which are, in fact, a perverse way of implementing the Rawlsian principle of the "veil of ignorance" over the real causes of the actual differences in a society, making this veil not "voluntary" but "imposed". ( ... ) We repeat, it risks becoming a false strategy of curing the symptoms of an illness without removing the causes-or because there is the precise will of not removing them, as it is the case of the social media manipulators behind populist movements. ([12], pp. 106-107)

However, the maximin principle, Sen noticed, can be used independently of Rawls' neo-Kantian normativism. More precisely, for making consistent the maximin criterion as an aggregation principle of variables within a SCT, we have to make it compatible with (a matrix of) $m$ different orderings of social states for $n$ different individuals (persons)—and not with one only $n m$ ordering like in Rawls' theory. Particularly, in the case of Sen's theory, in the interpersonal comparison of welfare states, we start from the relevance of the subjective differences, including not only the injustices and the inequalities in the resource distribution, but also the ethical and the cultural differences and preferences, the religious beliefs, and even the personal tastes. They determine, indeed, different subjective ways and grades of enjoying what are objectively the same commodities, and/or of using what are objectively the same utilities. In a word, they determine different individual positions in the welfare ranking for the same commodities/utilities that a suitable theory of justice as fairness must consider. All this transforms Rawls' "theory of distributive justice" into Sen's theory of a "comparative distributive justice".

In this connection, one of the main results obtained by Sen in SCT is his demonstration that the inconsistencies derived from the usage of the Rawlsian maximin principle in SCT ultimately reduce themselves to the usage of the Paretian axiom of unanimity in assessing the different welfare rankings in a SCT inspired by maximin fairness criteria. An axiom that, as we know, is the formal root of whichever "impossibility theorem in SCT" (see Section 2), and that, according to Sen, must be substituted by the axiom of extended identity among individual positions.

This axiom is a formal version of Adam Smith's extended sympathy principle, in the sense of "placing oneself in the position of another" ([19], p. 210). This principle is derived from Smith's book The Theory of Moral Sentiments, of which Sen himself edited a new edition, and for which he wrote an important "Introduction" [37]. Sen gave a formal version of this principle in terms of an axiom of extended identity among $n$ distinct welfare rankings and relative positions of persons and groups in SCT. Indeed, as far as, the SCT in Sen's quantitative approach allows a comparable grading of "gains" and "loss" 8 of commodities and utilities for different persons and groups in different social positions,

8 Effectively, as explained at length in the Chapter 9 (pp. 203-209), and in a formalized way in the Chapter 9* (pp. 210-218) of [19], Sen is here referring to a fundamental contribution of Patrick Suppes to SCT, in a paper published in 1966 [38], where he developed formally a "social decision function" based on the revolutionary principle of a grading of different level of justice, on an interpersonal and then equitable basis. Suppes' model is essentially a "2-individuals model", and the "grading justice principle" consists in a set of rules such that a given individual $i$ must judge a given social state $x$ as "more just" than $y$, either with respect to the consequences for himself, or with respect to the consequences for another individual. That is, $x$ is better than $y$ for an individual $i$ "if either (a) he prefers to be himself at $x$ rather than at $y$, and also prefers to be the other individual at $x$ rather than at $y$, or (b) he prefers to be himself at $x$ rather than the other individual at $y$, and prefers to be the other individual at $x$ rather than himself at $y^{\prime \prime}$ ([19], p. 205). As we see below, Sen makes consistent Suppes' model of SCT, by his axiom identity between individual preference rankings, through which he extends Suppes' model to $n$-individuals, and grants its logical universality by including in the identity also the individual tastes of the different persons. 
the axiom of "extended identity" allows us to use the maximin principle on a relative and not absolute basis as an aggregation principle of different welfare rankings based on the maximin principle for consistently fair social rankings of welfare states, one for each different context. That is, each of them is a partial ordering of social welfare states, not a total (complete) one, like in Rawls' normativism, or like in a SCT applying the Pareto unanimity axiom, like in Arrow's social welfare functions. On the contrary, Sen's application of the maximin criterion gives us a suitable quantitative parametrization of the welfare aggregates involved.

Without entering here in the formal demonstration given by Sen of this approach to SCT (see [19], pp. 210-220), for understanding the relevance of his "axiom of identity" it is better to illustrate by an example given by Sen himself what is the economic and social relevance of the personal differences for assessing a non-Paretian fair distribution of commodities/utilities in SCT. The paradoxical example concerns different ways of grading interpersonally some commodities, depending on different value systems of the persons involved ([19], pp. 207-210). The commodities in question are different amounts of "pork" and "beef", and the individuals involved are "a devout Muslim" (individual $i$ ) and "a devout Hindu" (individual $j$ ). It is obvious that the Muslim likes beef, but is disgusted by pork, and vice versa for the Hindu. Moreover, assuming free disposal, the Muslim is indifferent between different amounts of pork, and the same holds for the Hindu as to beef. The different outcomes corresponding to different social states are denoted as $x$ and $y$ according to the following Table 1 :

Table 1. Examples of comparative preferences.

\begin{tabular}{ccc}
\hline States & The Muslim $(i)$ & The Hindu $(j)$ \\
\hline State $x$ & 2 pork, 0 beef & 0 pork, 2 beef \\
State $y$ & 0 pork, 1 beef & 1 pork, 0 beef \\
\hline
\end{tabular}

If we apply the Pareto unanimity, it is evident that the state $y$ is better than the state $x$ for both, because the Muslim prefers 1 unit of beef to 2 units of pork, and the Hindu 1 unit of pork to 2 units of beef. If we apply, on the contrary, Suppes' grading principle of fairness (see note 8), extended to consider an interpersonal comparison of welfare states because of also including the "subjective tastes" ([19], p. 208), and based on the "extended sympathy" principle ("put oneself in the position of another"), it is obvious that state $x$, not $y$, is the better one. Indeed, it is evident that the Muslim prefers to be in the position $(x, j)$ of the Hindu ranking because 2 units of beef for him are better than 1 , while the Hindu prefers to be in the position $(x, i)$ of the Muslim ranking, because 2 units of pork are better than 1. At the same time, it is evident that the Muslim is indifferent between the positions $(x, i)$ and $(y, j)$, both having 0 units of beef, just as the Hindu is indifferent between the positions $(y, i)$ and $(x, j)$, both having 0 units of pork.

This extension of Suppes' grading principle has fundamental consequences for a model of SCT based on Sen's comparative distributive justice, because it allows to include coherently in the model both an utilitarian and a maximin criterion for variable aggregation overcoming the limits of both ${ }^{9}$.

If $x$ is more just than $y$ in the sense of Suppes (with the identity axiom imposed), then $x$ must have a larger welfare aggregate than $y$ (utilitarian relation) and also the worst-off individual at $x$ must be at least as well off as any individual at $y$ (maximin relation $)^{10}$. ([19], p. 208)

9 See the precedent discussion for the limitations of the maximin criterion in its Rawlsian version in SCT, and see note 7 for the limitations of the utilitarian criterion of justice that is the standard criterion in the liberalist approach to justice in economics.

10 In this last regard, Sen refers to the fundamental Theorems $9^{*} 5$ and $9^{*} 7$ in the formal version of the maximin criterion using Sen's extended version of Suppes' grading principle. This is the formal core of Sen's comparative theory of distributive justice, for which Sen is also able to give the appropriate quantitative measures in SCT applied to economic, social, and political decision procedures (see [19], pp. 216-218. See also pp. 337-394 for an update). 
As we see, the core of Sen's model of a comparative distributive justice applied to SCT is constraining Suppes' comparative grading principle of justice within Sen's axiom of identity.

The first step for understanding this axiom consists in extending the individual ordering (ranking) $R_{i}$ of social positions $(x, i),(y, i), \ldots$, where $(x, i)$ stands for "being in the position of the individual $i$ in the social state $x^{\prime \prime}$, over alternative social positions including also those of another individual $j,(x, i),(y, j), \ldots$, given that $i \neq j$. That is, individuals are not simply numerically distinct, but are also subjectively distinct, i.e., they are persons and not merely individuals. This extended ordering is denoted as $\widetilde{R}_{i}$ and defined as the "Cartesian product" (i.e., the set of all possible combinations) of $X$ and $H, X \times H$, where $X$ is the set of social states and $H$ is the set of all individuals.

However, for applying Suppes' grading principle based on an "extended sympathy" between only two different individuals to $n$ individuals making comparable their social positions, it is necessary to impose a restriction over the set $H$ of individuals. That is, it is necessary to impose the restriction of a one-to-one correspondence from the set of individuals $H$ to $H$ itself, such that $i=\rho(j)$, where $\rho$ is a transformation mapping a person $j$ onto a person $i$. The set of all this one-to-one-correspondences can be denoted as $T$ and justifies Suppes' assertion that " $x$ is more just than $y$ according to person $i$ ", $x J_{i} y$, so that, given the transformation $\rho$, this justifies $i$ in assessing that she prefers to be in the position of someone, either $j$ or $i$ herself, in $x$ than in the position of this same person in $y$ (see Table 1). This means that the ordering obtained in such a way is not a total or complete ordering of social states, but only a partial one: It concerns the ranking between social states of $n$ persons to which $\rho$ applies ${ }^{11}$. On the other hand, in societies as complex as ours, the pretension of having complete social orderings for justifying social decisions is a void, useless, and even dangerous pretension. Even though this means from the social and political standpoints that an effective and fair governance can be only on a local basis and so, in politics this means the necessity of redefining the relationships between the central State and the local entities accordingly.

Therefore, with the restriction $\rho$ imposed on the extended ranking $\widetilde{R}_{i}$, i.e., $\widetilde{R}_{i}^{\rho_{12}}$, the axiom of identity formalizing in SCT Smith's "extended sympathy" principle, and then inserted in the theory on "ethical grounds", can be stated as following ([19], p. 214):

Axiom 1. (Axiom of identity). Each individual $j$ in placing himself in the position of person $i$ takes on the tastes and the preferences of $i$. That is,

$$
\forall x, y \in X:\left[\forall i:\left\{(x, i) \widetilde{R}_{i}^{\rho}(y, i) \leftrightarrow \forall j:(x, i) \widetilde{R}_{i}^{\rho}(y, i)\right\}\right]
$$

A stronger version of the Axiom 1 is the following "axiom of complete identity" identifying the rankings among all the persons, i.e.,

Axiom 2. (Axiom of complete identity). $\forall i, j: \widetilde{R}_{i}^{\rho}=\widetilde{R}_{j}^{\rho}$.

It is trivial, Sen notices, that under the axiom of complete identity $J_{i}=J_{j}$ for all persons $i, j$, the indices in referring both to $J$ and $R$ become useless.

To sum up, we can share with Sen the conviction that a proper theory of justice as fairness requires necessarily the introduction in SCT of the possibility of interpersonal comparison of well-being.

11 This passage of Sen is particularly significant. "The capability approach is entirely consistent with reliance on partial rankings and limited agreements. The main task is to get the weights—or ranges of weights-appropriate for the comparative judgements that can be reached through reasoning, and if the result is a partial ranking, then we can make precisely those judgements that a partial ranking allows" ([19], p. 369).

12 For the sake of clarity, and differently from Sen, I preferred to emphasize here the restriction $\rho$ in the symbolism, because it is the key-notion in Sen's theory. Effectively, Sen emphasizes the dependence on $\rho$ for defining furtherly (see [19], p. 217) a "weaker version", $x O_{i} y$, of Suppes' justice relationship $x J_{i} y$, where the restriction $\rho$ is interpreted as a selection principle of persons for which the relationship works, in order to make the procedure computable by avoiding the exponential explosion of the possible combinations (see below): $x O_{i} y \leftrightarrow \exists \rho \in T:\left[\forall j:(x, j) \widetilde{R}_{i}(y, \rho(j))\right]$. Indeed, it can be demonstrated that the $x O_{i} y$ is sufficient for justifying consistently the maximin aggregation principle is SCT. 
If we can make comparisons between social states on the basis of interpersonally comparable information about different persons, many possibilities of making systematic social welfare judgements open up. ( ... ) This is exactly where our ethical concerns such as equity, or removal of deprivation, or enhancement of people's freedoms can enter into the discussion, and find a place in our critical scrutiny. ([19], pp. 338-339)

A very simple numerical evidence of the richness of the possibilities that the interpersonal comparability of social states opens to SCT is given by Sen himself when he recalls to us that the extension of Suppes' $x J_{i} y$ comparative justice relation to $n$ individuals just discussed means that, while in a two-person world like in Suppes' approach, there are only two personal permutations, there are as many as $3,628,800$ permutations in only a ten-person world. Indeed, the number of permutations is given by $n$ !, i.e., $n(n-1)(n-2)(n-3) \ldots 1$ possible permutations. This means that while the Pareto relation is concerned with only one-to-one correspondence, there are 3,628,800 different ways in which a state $x$ can be more just than $y$ simply in a ten-person society. On the other hand, the "exponential explosion" of the possible combinations related with $n$ ! that for a $n$ sufficiently large would saturate any computational capability either human or artificial, makes highly significant the application of the $\rho$ restriction to Suppes' $x J_{i} y$ relation in terms of $x O_{i} y \leftrightarrow \exists \rho \in T:\left[\forall j:(x, j) \widetilde{R}_{i}(y, \rho(j))\right]$. Indeed, Sen's $x O_{i} y$ is a necessary and sufficient condition for justifying the consistency of the maximin principle in SCT (see note ${ }^{12}$, and [19], p. 217).

For our theoretical aims of searching for correctives to the actual crisis of the liberal vision of society, as Sen emphasizes many times in his writings, all this means is that the relevance of the interpersonal information exchanges is against another pillar of the liberal economic and social sciences, and of its mathematics. Indeed, since the famous textbook of Paul Samuelson that inaugurated the modern mathematical analysis in economy [39], the liberal theory considers as irrelevant the interactions among the individual economic actors. In this regard, some scholars recently noticed [12] that not casually the Samuelson textbook considers as the physical paradigm of reference in studying the stability of economic systems using the instruments of the statistical analysis, the Gibbs "thermodynamics of gases", based on statistical mechanics, to which the first two chapters of Samuelson's textbook are dedicated.

On the other hand, as the same Arrow and Sen, together with many other economists noticed [40], the impact of the information exchange among individuals in the mathematical modeling of economic and social systems does not depend today only on ethical concerns, but it is a matter of fact related with the actual "internet revolution". Indeed, fast information exchange determines the fast "formation/dissolution" of groups of individuals, characterized by coherent ways of behaving for short time intervals, often on a worldwide dimension, both in financial markets and more generally in our "liquid society". In politics also, the "erratic behavior" of the electorates is another manifestation of the same phenomenon that put the political parties onto the quicksand of the research of an immediate and vanishing consensus. All this means is that not the thermodynamics of gases, but the thermodynamics of fluids in condensed matter physics must be today the mathematical reference model for the formal philosophy, in economic, social, and political sciences [13] ${ }^{13}$.

12 For the sake of clarity, and differently from Sen, I preferred to emphasize here the restriction $\rho$ in the symbolism, because it is the key-notion in Sen's theory. Effectively, Sen emphasizes the dependence on $\rho$ for defining furtherly (see [19], p. 217) a "weaker version", $x O_{i} y$, of Suppes' justice relationship $x J_{i} y$, where the restriction $\rho$ is interpreted as a selection principle of persons for which the relationship works, in order to make the procedure computable by avoiding the exponential explosion of the possible combinations (see below): $x O_{i} y \leftrightarrow \exists \rho \in T:\left[\forall j:(x, j) \widetilde{R}_{i}(y, \rho(j))\right]$. Indeed, it can be demonstrated that the $x \mathrm{O}_{i} y$ is sufficient for justifying consistently the maximin aggregation principle is SCT.

13 For understanding intuitively this stance, it is sufficient to recall that in the case of the thermodynamics of gases in the Lagrange equation - that is, the master equation for modeling dynamic systems in physics—and in the consequent Hamiltonian equation - that models the evolution in time of a dynamic system —only the kinetic term of energy is considered. In fact, as Boltzmann taught us, the thermodynamic macroscopic variables (heat, pressure, and volume) depend only on the statistical distributions of velocity of the individual non-interacting particles composing the gas at the microscopic level. 
Of course, this holds in a straightforward way for Sen's economic theory based on a comparative distributive theory of justice that makes him the only economist of a worldwide relevance in the modern panorama, who put the person, i.e., the individual-in-relationship, and the person flourishing, i.e., the person's "capabilities" and "functioning's" achievement, at the center of the economic sciences, and of the economic, social, and political decision processes modeled in SCT. In this regard, one of the main limitations impeding the wide and generalized usage of Sen's theory in micro- and macro-economy is the necessity of using a dynamic and not purely statistical weighing of the model variables, as Sen himself affirmed many times in his works, overall recently. For instance, we could consider the income as a variable by which everyone's advantages can be valued and impersonally compared. However, Sen emphasizes ([19], p. 358),

real income comparisons involve aggregation over different commodities, and in judging comparative individual advantages there is the further problem of interpersonal comparisons, taking note of variations of individual conditions and circumstances. It is, of course, possible to reflect these variations in values of 'adjusted income' that can be appropriately defined, but that is only another way of stating the same problem, requiring that attention be paid to the valuation of heterogeneous factors (... ). One way or another, the issue of valuation and weighing has to be faced.

Indeed, generally, when we take into account in physics, as well as in economic and social models, the inner interactions among the system components, all the usual mathematical and computational tools of statistical analysis used both by humans and by AI systems, appear inadequate. This depends on the fact that they, in one way or another, necessarily suppose a fixed and then unique set of statistical weights for evaluating the variables-after a hand-made (for human reasoning) or automated (for artificial reasoning) "learning phase" on some representative sample of the data set. This limitation does not depend only on the higher order correlations present in the data set making in principle not appliable the classical methods, because all "flattening" the differences onto an average distribution (first order correlation) of some "equilibrium point" 14 , but on the fact that these inner correlations are continuously changing because of the interactions among the system components. This would require a dynamic, always updating learning procedure. However, these intrinsic difficulties as to the classical statistical approach in economic and social sciences led to the diffused judgement among scholars, quoted by Sen himself, that his theory "is not practically usable because of the weighing problem" ([19], p. 369) ${ }^{15}$.

\section{Concluding Remarks}

In this paper, I discussed some of the main aspects of the actual crisis of the liberal model of economy and society that are also actually impinging on the democratic political institutions, because of the growing impoverishment of the populations on a worldwide dimension, intensified by

On the contrary, in the thermodynamics of fluids, for obtaining the statistical distributions of particle condensates, it is necessary to consider in the Lagrangian and in the Hamiltonian also the term of potential energy. That is, the energy related with the particle interactions, e.g., the electromagnetic force exchanges on which, in condensed matter physics, the molecule formation and the molecular aggregates formation in the liquid and solid states of matter critically depend.

14 In parentheses, this is the main criticism of Sen to Suppes' mathematical model of comparative justice that admits one only "point of justice" as an equilibrium point that makes indistinguishable the different strategies used by the two players for reaching it, because of their different value systems. This depends on the fact that in Suppes' model "there is no requirement that one must take on the subjective features (in particular tastes) of the other when one places oneself in his position. This is the source of the trouble" ([19], p. 207). Ethically, indeed, this means that I am justified in imposing on the other person my own strategy for reaching the shared target, without respecting her traditions or value system. This is the core of the "cultural colonialism" that weakened the diffusion of the Western values among other cultures, e.g., in Islamic countries.

15 "The capability approach is entirely consistent with reliance on partial rankings and limited agreements. "The main task is to get the weights-or ranges of weights-appropriate for the comparative judgements that can be reached through reasoning, and if the result is a partial ranking, then we can make precisely those judgements that a partial ranking allows" ([19], p. 369. Italics are mine). 
the financial crisis of 2008, and much more by the 2020 Covid-19 pandemic crisis. The depth of the crisis is also risking involving the political institutions and the same idea of democracy based, in the Western countries, on the Enlightenment philosophy that informed the Liberal approach to political philosophy. In this sense, a further component of the crisis of the Liberalism principles and the consequent "decline of the West" is the overwhelming arrival into the world economic, political, and also military scenario of countries like China, India, the Islamic countries of the oil economy, and partly the same Russia, which never knew in their cultural traditions the Enlightenment. A further acceleration factor of the worldwide economic, social, and political system crisis is the irruption of the "informatic revolution". Before all, for the necessary redefinition of the job market, related with the fast automatization and robotization, not only of manufacturing repetitive works, but also of many other jobs related with services, and even with complex control and decision processes, through the development of AI autonomous systems. Moreover, the development of the internet also changed the classical tools of the political discussion and of the formation of the public opinions, and determined a crisis of the "representative democracy" model. This is causing a dangerous shift toward forms of an internet-driven "direct democracy" or "e-democracy", theorized by some scholars and policy makers, ignited by the growth of the populist movements because of the economic and social crisis, and falsified by the manipulation of the consensus through a fraudulent usage of the net by hidden and often foreign powers.

All this requires a deep revision of the classical liberal approach to economy and politics that points in the direction of a revision of the utilitarian ethics in economy, and of the egalitarianism ethics in politics, toward the development of an ethics based, both in economy and in politics, on the idea of justice as fairness. Indeed, without implementing an idea of justice that considers the effective and then equitable access and enjoyment of people to the economic commodities, utilities, and growth opportunities, as well as their equitable access to the "basic liberties" of the liberal vision, both the utilitarian ethics of profit in economy, and the idea of political equality of citizens in politics become abstractly generic, and effectively the source of manifest injustices. Effectively-and the 2020 crisis accelerated this drift-they both become the prerogative of some elites, undermining the foundations of the liberal democracy, and of the liberal vision of society, igniting at the same time the protest of the populist movements.

I discussed, therefore, two main representatives of this revision of the classical Liberal Tradition based on the idea of justice as fairness, adequate for a pluralistic society such as ours: John Rawls and Amartya Sen. Rawls proposed his political theory, searching for Righteous Institutions that satisfy the principles of justice as fairness, because based on the maximin ethical criterion for an equitable distribution and access to the economic commodities and utilities, as well as to the political "basic liberties". In this sense, for the absolute relevance of Rawls' work and of his liberal approach in the contemporary debate in political sciences, he constitutes a real "turning point" in this discipline. Indeed, nobody can today work in this discipline while disregarding his contribution, either agreeing, or disagreeing with it. We also discussed the limitations of Rawls' approach to the notion of fairness, as far as also depending on an abstract Kantian normativism. Indeed, this led him to grant ethical universality to the notion of fairness, by proposing the "thought experiment" of the original position, and the consequent veil of ignorance about the personal differences of religion, culture, gender, social and economic position, etc. that must characterize the policy makers for becoming impartial civil servants of all citizens. A sort of abstract or "ascetic" requirement that anyway poses several problems to the notion of "representative democracy" in politics.

I discussed afterward Amartya Sen's approach to the theory of justice as fairness, because depending historically and theoretically on Rawls' theory, but correcting it because renouncing to any form of normativism. Sen, indeed, proposed a theory of comparative distributive justice that is revolutionary in many senses. Before all, because it grants "universality" not by referring to only one reference frame of fairness like Rawls" "original position" that for being abstractly valid for all, effectively it applies really to nobody. Sen, on the other hand, does not work in political philosophy, 
but in a newborn discipline, the SCT, formalized by using in it the axiomatic method, a theory that Sen himself contributed definitely to create, and that can apply in whichever collective decision process, all aimed at passing consistently from individual rankings of preferences of social states, to only one social ranking, so to justify collective choice procedures. SCT models therefore apply to economic, social, and political sciences, and for their formal character are suitable for making an algorithmic version of them, to grant the necessary AI support to complex human decision processes. This means that universality is granted in SCT by the logical consistency of the proposed reasoning (calculus), making it repeatable whenever and everywhere, by applying the same axioms and rules.

In other words, it is not necessary, for avoiding arbitrariness or relativism, in a comparative theory of justice as fairness to refer to some absolute criterion of fairness like Rawls' original position, that from the standpoint of SCT would signify an optimal (i.e., maximal for all contexts) fair ranking of social states satisfying distributive justice criteria like the maximin principle, because supposing a complete or total ordering (ranking) of social states. This supposition is, indeed, untenable in a complex and pluralistic society like ours, so that any SCT model supposing it becomes simply misleading. The revolutionary contribution of Sen is the demonstration that it is sufficient to grant universality having only partial orderings, satisfying a maximality criterion of fairness for a given context, if it is available a transform mapping each partial ranking over the other for $n$-individual preference rankings, making then operational Smith's "extended sympathy" ethical principle of "putting oneself into the position of the other". This principle is formally written by Sen as a powerful Axiom 1 (Axiom of identity) among quantitatively comparable social positions.

We therefore reconstructed the main lines of the theoretical itinerary leading Sen to develop a SCT based on his revolutionary theory of a comparative distributive justice that is effectively an original synthesis between Aristotle's theory of fairness, where economic commodities and utilities are considered as means not ends for the goal of personal flourishing, and Smith's theory of extended sympathy as the core of a comparative approach to a fair distributive justice. This synthesis allowed Sen to develop his personalistic approach to economical sciences of the "capabilities" and "functioning's", where the personal flourishing consists in the achievement of the personal capabilities into "functioning's", that is, into "valued and valuable ways of being and of doing", according to the different value systems of persons and groups.

To conclude, a concrete example of application of Sen's "extended sympathy principle" in social choices, respectful of the different personal beliefs and value systems-Sen is openly an atheist-for pursuing a shared ranking of preferences informing "just and equitable" social, economic, and political collective choices, can be taken from Sen's biography. This is the open and repeated support of Sen to Pope Francis' "ecological encyclic" Laudato sì (2015), and to his underlying personalistic "human centered" approach to economy, leading both of them to fight common battles such as that for "the food entitlement for poor peoples" by the UN. Quoting directly from Sen's word about Pope Francis,

I would say that He is the only person who is in a recognized position of authority and who is thinking about issues regarding Humanity, this makes of course the difference in this world, but it is not necessary to be religious or Catholic... because Francis in doing so represents not only the Head of the Catholic Church, but He is the Head who speaks for Humanity in the sense that He acts in a way to get people thinking on these issues. [41]

Effectively, several authors [42-44], myself included [13,14,20], emphasized the objective convergences between Sen's social and economic theory and the Social Doctrine of the Catholic Church, as far as both propose a human-centered approach to economy and then to social and political issues. This led to the more recent invitation of Sen by the Catholic Church as a keynote speaker to the World Conference: "The Economy of Francesco", organized (effectively re-scheduled because of Covid-19) for 19-21 November 2020 in Assisi (Italy), the city of St. Francis (https://francescoeconomy.org/).

For our aim of suggesting correctives to the actual crisis of the Liberalism and then of the Western Civilization, one of the more revolutionary point with respect to the Liberal Tradition is of no-longer 
ignoring — or even fighting against—religions and religious groups and institutions, by considering them simply irrational, and then opposed to the modern economic development, and to the modern idea of human progress, like in the more fanatic positions of the Enlightenment. This refusal could be true today only for some fundamentalist religious positions and groups-evidently unable to exert an "extended sympathy" toward other people with different convictions, either religious or atheistic. This is, however, not true for the vast majority of religious persons and peoples that today constitute also the vast majority of world population-effectively, at 2010, the $84 \%$ according to the Pew Research Center statistical analysis [45]. On the contrary, in front of the dramatic economic, social, and ecological crises all strictly inter-related, the real question at issue is how to mobilize this enormous ethical and social work reservoir of the religions-overall in the developing and poorer countries where the religious influence is stronger-for the common construction of a more just and equitable form of economy and of society, for pursuing the common goal of a sustainable and integral development of persons and peoples. In this context, Sen's capabilities approach and his methodology of the extended sympathy, being respectful of the different Traditions and Faiths, can give a suitable methodic grounding for "engaging development and religions". Overcoming, therefore, the old Enlightenment opposition between the "secular" organizations, and "the faith communities as if they were separate entities, with the latter to be used for the former ends". This, evidently, according to the old "colonialist logic" that weakened and made detestable Western civilization among the developing countries' populations. On the contrary, the true question at issue is,

"how do development actors, religious and secular, apply their beliefs and values to development programs, and how does the local contexts influence the application of these beliefs and values?". ([42], p. 111)

In this framework of a new alliance between "the secular and the religious" for solving together the many challenges we are faced, it resonated as an out-of-date cacophony the recent vindication of an absurd "freedom of blasphemy" by the President of a Country that was "the Motherland" of the modern conception of the State based on the principles of "equality, fraternity, liberty", in the solemn context of an official ceremony on 4 September 2020, held at the Paris Pantheon, for celebrating the 150th anniversary of the France Third Republic Proclamation, and the naturalization of some new citizens [46]. Addressing to them, against any temptation of "Islamic separatism" for which the France Government was preparing a future specific law, President Macron solemnly stated that to be French means that "you are not choosing a part of France. You choose France ... the Republic will never allow any separatist adventure". Of course, this is in principle perfectly acceptable. The problem is in the declination of such a principle of cohesive unity of a State that effectively points in the opposite direction because not considering the personal character of the individuals composing a unified community. Indeed, "freedom in France", the President continued, includes "the freedom to believe or not to believe. But this is inseparable from freedom of expression, up to the right to blasphemy"16.

Significantly, many commentators emphasized the "unfair character" of these words, and the fear, for the future law against the religious separatism, of being as much unfair in stigmatizing France's largely moderate Muslim population, the largest in western Europe. More generally, Macron's vindication among the modern "basic liberties" of an absurd "right to blasphemy" is revelatory of the deviation toward libertarianism of an abstract equalitarianism. It arrives indeed to negate the right (liberty) for religious persons and groups of expressing publicly the identity symbols of their faith, at the same time vindicating the right (liberty) of non-believers of publicly offending the convictions of believers. This macroscopic lack of fairness between believers and not-believers is the exact opposite

16 The reference, of course, was to the blind, fanatic violence that bloodied Paris over the terroristic attacks in January 2015 on the Charlie Hebdo newsroom because of the publication of cartoons mocking the Prophet Muhammad, and on a kosher supermarket. This attack killed 14 people-17 if the France-born terrorists included-and inaugurated a long season of violence by the armed groups of ISIL (ISIS) in France and in Europe. 
of Rawls' notion of justice as fairness, always respectful of the personal "comprehensive" convictions and of their manifestation, as far as they are not imposed to the others from power positions, and, overall, we add, are not diverting into criminal terroristic attacks. However, overall, this unfair position of vindicating a right to blasphemy is against the "extended sympathy" ethics-the ethics of dialogue - of Smith and Sen, based not on the negation of the differences like in the equalitarianism, but on the capability of a person to put herself in the position of another, respectful of the reciprocal differences in pursuing the common good in a reconciled society.

Funding: This research received no external funding.

Acknowledgments: I thank Gianfranco Basti, of the Faculty of Philosophy of the Pontifical Lateran University, for the illuminating discussions about Section 3 of this paper.

Conflicts of Interest: The author declares no conflict of interest.

\section{References}

1. Tirole, J. Economics for the Common Good; Princeton, UP: Princeton, NJ, USA, 2017.

2. Stiglitz, J.E.; Sen, A.; Fitoussi, J.-P. The report by the Commission on the measurement of economic performance and social progress. In Mis-Meauring Our Lives. Why GDP Doesn't Add Up; With a foreword by Nicolas Sarkozy; The New Press: New York, NY, USA, 2010.

3. Manyika, J.; Chui, M.; Miremadi, M.; Bughin, J.; George, K.; Willmott, P.; Dewhurst, M. A Future that Works: Automation, Employment, and Productivity; A McKinsey Global Institute Research; McKinsey \& Co.: New York, NY, USA, 2017.

4. Mulgan, G. Big Mind: How Collective Intelligence can Change Our World; Princeton, UP: Princeton, NJ, USA, 2018.

5. Birhane, A.; Cummins, F. Algorithmic Injustice: Toward a Relational Ethics. arXiv Preprint 2019, arXiv:1912.07376. Available online: https://arxiv.org/pdf/1912.07376v1.pdf (accessed on 9 April 2020).

6. Basti, G.; Capolupo, A.; Vitiello, G. Ethical Responsibility vs. Ethical Responsiveness in Conscious and Unconscious Communication Agents. Proceedings 2020, 47, 68. [CrossRef]

7. Taddeo, M.; Floridi, L. How AI can be a force for good. Science 2018, 361, 751-752. [CrossRef] [PubMed]

8. Pontifical Academy for Life. Rome Call for AI Ethics. 28 February 2020. Available online: http://www.academyforlife.va/content/dam/pav/documenti\%20pdf/2020/CALL\%2028\%20febbraio/ AI\%20Rome\%20Call\%20x\%20firma_DEF_DEF_.pdf (accessed on 4 March 2020).

9. Sinibaldi, E.; Gastmans, C.; Yáñez, M.; Lerner, R.M.; Kovács, L.; Casalone, C.; Pegoraro, R.; Paglia, V. Contributions from the Catholic Church to ethical reflections in the digital era. Nat. Mach. Intell. 2020, 2, 242-244. [CrossRef]

10. Formal Philosophy. Aim, Scope, Direction; Hendricks, V.F., Symons, J., Eds.; Automatic Press/VIC: Copenaghen, Denmark, 2005.

11. Hansson, S.; Hendricks, V.F. Introduction to Formal Philosophy; Springer: Berlin, Germany; New York, NY, USA, 2018.

12. Basti, G.; Vitiello, G. The computational challenge of Amartya Sen's social choice theory in formal philosophy. In The Logic of Social Practices; Giovagnoli, R., Lowe, R., Eds.; Springer: Berlin, Germany; New York, NY, USA, 2019.

13. D'Amodio, A. I limiti della democrazia del consenso e il ruolo dei corpi intermedi dello stato. Arkete 2019, 3-4, 55-70.

14. D'Amodio, A. Virtual Speech Acts. January 2016. Available online: https://aisb.org.uk/convention-proceedings/ (accessed on 25 August 2020).

15. Hirschkop, K. Mikhail Baktin: An. Aesthetic for Democracy; Oxford UP: Oxford, UK, 1999; pp. 249-271.

16. Fuller, R. Beasts and Gods: How Democracy Changed its Meaning and Lost Its Purpose; Zed Books: London, UK, 2015.

17. Gimmier, A. Deliberative democracy, the public sphere, and the internet. Philos. Soc. Crit. 2001, 27, 21-39. [CrossRef]

18. Sen, A.K. Collective Choice and Social Welfare; Elsevier: Amsterdam, The Netherlands, 1970; Available online: https://www.sciencedirect.com/book/9780444851277/collective-choice-and-social-welfare (accessed on 11 September 2020).

19. Sen, A.K. Collective Choice and Social Welfare, Expanded Edition; Penguin: London, UK, 2017; Available online: https://www.penguin.co.uk/books/290/290088/collective-choice-and-social-welfare/9780141982502. html (accessed on 11 September 2020). 
20. D'Amodio, A. Libertà, Giustizia e Sviluppo. Sturzo, Rawls e Sen: Un Dialogo Inaspettato; Solfanelli Editore: Chieti, IT, USA, 2020.

21. Maffettone, S.; Veca, S. L'Idea di giustizia da Platone a Rawls; Editori Laterza: Roma, Italy; Bari, Italy, 2012.

22. Rawls, J. A Theory of Justice, Revised Edition; Belknap Press: Cambridge, UK; An Imprint of Harvard University Press: Boston, MA, USA, 1999.

23. Nozick, R. Anarchy, State, and Utopia; Balckwell: Oxford, UK; Cambridge, MA, USA, 1974.

24. Rawls, J. Political Liberalism; Columbia University Press: New York, NY, USA, 1996.

25. Kant, I. An answer to the question: What is enlightenment? In Practical Philosophy, Gregor, M.J., Ed.; The Cambridge Edition of the Works of Immanuel Kant; Cambridge UP: Cambridge, UK, 1999; pp. 11-12.

26. Rawls, J. Justice as Fairness. A Restatement; Belknap Press: Cambridge, MA, USA, 2001.

27. Spencer, M.J. Ethical School Leadership; Rowman \& Littlefield Education: Lanham, ML, USA, 2002.

28. Royal Swedish Academy of Sciences. Amartya Sen. The Sveriges Riksbank Prize in Economic Sciences in Memory of Alfred Nobel 1998. 10 December 1998. Available online: https://www.nobelprize.org/prizes/econ omic-sciences/1998/sen/facts/ (accessed on 19 August 2020).

29. Sen, A.K. The Possibility of Social Choice. Nobel Lecture. Am. Econ. Rev. 1999, 89, 178-215. [CrossRef]

30. Arrow, K.J. Social Choice and Individual Values, 2nd ed.; Yale UP: New Haven, CT, USA; London, UK, 1963.

31. de Condorcet, M. Essai sur L'application de L'analyse à la Probabilité des Decisions Rendues à la Pluralité des Voix; L'Imprimerie Royale: Paris, France, 1785.

32. Endriss, U. Logic and social choice theory. In Logic and Philosophy Today; Gupta, A., Van Benthem, J., Eds.; College Publications: London, UK, 2011; pp. 333-377.

33. Sen, A.K. The impossibility of a Paretian liberal. J. Political Econ. 1970, 78, 152-157. [CrossRef]

34. Sen, A.K. The Idea of Justice; Penguin Book: London, UK, 2010.

35. Sen, A.K. Development as Freedom; Anchor Books: New York, NY, USA, 2010.

36. Rawls, J. The priority of rights and the idea of good. Philosohy Public Aff. 1988, 17, 251-276.

37. Smith, A. The Theory of Moral Sentiments. With an Introduction of Amartya Sen; Penguin: London, UK, 2009.

38. Suppes, P. Some formal models of grading principles. Synthese 1966, 16, 284-306. [CrossRef]

39. Samuelson, P.A. Foundations of Economic Analysis; Harvard UP: Cambridge, MA, USA, 1947.

40. Sen, A.K. The Informational Basis of Social Choice. In The Arrow Impossibility Theorem; Maskin, E., Sen, A.K., Eds.; Columbia UP: New York, NY, USA, 2014; pp. 67-100.

41. La Stampa. Francis and Sen, the Door Opened by the Idea of Food Entitlement. 24 July 2015. Available online: https://www.lastampa.it/vatican-insider/en/2015/07/24/news/francis-and-sen-the-door-opened-bythe-idea-of-food-entitlement-1.35244283?refresh_ce (accessed on 9 August 2020).

42. Deneuline, S.; Zampini-Davies, A. Engaging development and religion: Methodological groundings. World Dev. 2017, 99, 110-121. [CrossRef]

43. Verstraeten, J. Catholic social thought and Amartya Sen on justice. In Economics as Moral Science. Virtues and Economics; Springer: Berlin, Germany; New York, NY, USA, 2017; pp. 215-223.

44. Deneulin, S. Integral Human Development through the Lens of Sen's Capability Approach and the Life of a Faith Community at the Latin American Urban Margins. Available online: https://kellogg.nd.edu/integral-human-de velopment-through-lens-sen $\%$ E2\%80\%99s-capability-approach-and-life-faith-community-latin (accessed on 25 August 2020).

45. Pew Research Center. The Global Religious Landscape. Available online: https://www.pewforum.org/2012/ 12/18/global-religious-landscape-exec/ (accessed on 28 August 2020).

46. FR24 News. Macron denounces Islamic separatism and defends the right to blasphemy. Available online: https://www.fr24news.com/a/2020/09/macron-denounces-islamic-separatism-and-defends-the-r ight-to-blasphemy-news-france.html (accessed on 5 September 2020).

Publisher's Note: MDPI stays neutral with regard to jurisdictional claims in published maps and institutional affiliations. 